\title{
Estimation of fines amount in syariah criminal offences using adaptive neuro-fuzzy inference system (ANFIS) enhanced with analytic hierarchy process (AHP)
}

\author{
Ahmad Fitri Mazlam, Wan Nural Jawahir Hj Wan Yussof, Rabiei Mamat \\ School of Informatics and applied Mathematics, Universiti Malaysia Terengganu, Malaysia
}

\begin{tabular}{l} 
Article Info \\
\hline Article history: \\
Received Feb 15, 2019 \\
Revised Apr 18, 2019 \\
Accepted Jun 10, 2019 \\
\hline Keywords: \\
Adaptive neuro fuzzy inference \\
system (ANFIS) \\
Amount of fines \\
Analytic hierarchy process \\
(AHP) \\
Syariah criminal
\end{tabular}

\section{Corresponding Author:}

\begin{abstract}
All syariah criminal cases, especially in khalwat offence have their case-fact, and the judges typically look forward to all the facts which were tabulated by the prosecutors. A variety of criteria is considered by the judge to determine the fines amount that should be imposed on an accused who pleads guilty. In Terengganu, there were ten (10) judges, and the judgments were made by the individual decision upon the trial to decide the case. Each judge has a stake, principles and distinctive criteria in determining fines amount on an accused who pleads guilty and convicted. This research paper presents an Adaptive Neuro-fuzzy Inference System (ANFIS) technique combining with Analytic Hierarchy Process (AHP) for estimating fines amount in Syariah (khalwat) criminal. Datasets were collected under the supervision of registrar and syarie judge in the Department of Syariah Judiciary State of Terengganu, Malaysia. The results showed that ANFIS+AHP could estimate fines efficiently than the traditional method with a very minimal error.
\end{abstract}

Copyright $(2019$ Institute of Advanced Engineering and Science. All rights reserved.

Wan Nural Jawahir Hj Wan Yussof,

School of Informatics and Applied Mathematics,

Universiti Malaysia Terengganu,

21030 Kuala Nerus, Terengganu Darul Iman, Malaysia.

Email: wannurwy@umt.edu.my

\section{INTRODUCTION}

Decision making is the process of helping someone solves the problem by assessing alternative resolution. It is a mandatory activity in real life which involves several steps including identifying the results and gathering information. Typically, many uncertainties and inaccurate data and criteria are used to make decisions. Sometimes, it seems natural to decide, but when it comes to multi-criteria to be considered, the decision-making process becomes a fuzzy task.

Since decision-making can be regarded as human needs, there are techniques used by people to deal with the problems. Traditionally, people always hold meetings between experts, vote for majority decisions and jump to a conclusion to end the process. This process is somewhat subjective. Therefore, modern methods of decision making have been introduced rapidly over several decades. In 1992, [1] discussed several methods of multi-criteria decision making and they updated the article in 2008 [2].

Adaptive Neuro-Fuzzy Inference System (ANFIS) method is one of the most widely used approaches to handle the multi-criteria decision-making process. ANFIS is a fuzzy inference system that has been used in numerous areas of research such as diagnosis [3-7], modelling [8] and prediction [9]. In diagnosis application, ANFIS was employed for risk diagnosis risk in dengue patients [3]. The use of the ANFIS for the diagnosis of malaria has been performed by [4] to provide better decision than the traditional diagnosis of methods characterized by erotic guesswork and patient observations by doctors. This work achieves a very close result to the expectation of the researchers with a very minimal error. Another diagnosis works using ANFIS was presented in [5-7], as a base for hypertension diagnosis and for 
heart disease diagnosis, respectively. Besides diagnosis, ANFIS model was used to forecast the return on stock price index of the Istanbul Stock Exchange (ISE) [8] and predict the future actions of the exchange rate [9].

Meanwhile, Analytic Hierarchy Process (AHP) is a method to find a weight between factors. AHP measures all the factors involved in the decision-making process through pairwise comparison. The comparison is conducted using a scale of absolute judgement that represents how vital one factor to one another and its also been used by researchers in many fields and researches. [10] shows an implementation of AHP in identifying the factors associated with obesity. The result indicated that the factor of Sedentary Lifestyle (SED) contributes the highest weight compared to Medical Psychiatric Illness (MED) and Genetics (GEN).

Based on the strength of ANFIS and AHP reported in the literature, this paper presents how ANFIS+AHP could help syarie judge to estimate fines amount to the khalwat offences based on five criteria before trial without interfering of influence judicial decision. These criteria are chosen because there are only five criteria that have been noted in the case fact tabulated by the enforcement officer for prosecution. Data that has been collected is a combination of different judges based on five criteria. In current practice, some judges estimate a meagre amount of fines while some judges put a very high amount of fines for the same criteria. In the previous study [11], we only implemented ANFIS for the same case study. Therefore, this paper aims to improve previous work by incorporating ANFIS with AHP.

The remainder of this paper is organized as follows: Section 2 discusses on the basic definition for ANFIS as a method used for estimating fines amout. Section 3 defines a simple step for AHP. A framework for estimation fines amount using ANFIS+AHP is presented in Section 4. Experimental results and discussion are tabulated in Section 5 and finally, Section 6 will conclude the paper.

\section{METHODOLOGY}

In this paper, 75 cases were trained, and 30 cases were tested with ANFIS solution. Then AHP solution is used to determine the weightage and finally the ANFIS+AHP solution is used to generate a new result.

\subsection{ANFIS solution}

This study used datasets from the Department of Syariah Judiciary State of Terengganu which is an institution that has Appeal Court, High Court and Sub Ordinary Court. Observation, literature survey and interview were used to gather information about the accused person who pleaded guilty and fines amount charged to that person. In this study, 75 datasets cases sentenced by fines were collected. Table 1 lists the attributes of Khalwat dataset while Table 2 lists the value of sex, marital status, location type of arrest and the time of arrest. The figure of age and the fines amount is used as the value for age and fines attributes accordingly. Table 3 shows the raw dataset that had been collected and the set of data that has been converted into value is shown in Table 4.

Table 1. Attributes of khalwat offences dataset

\begin{tabular}{ccc}
\hline Abbreviation & Decsription & $\begin{array}{c}\text { Representation of } \\
\text { Fuzzy Variables }\end{array}$ \\
\hline age & Age in years & $x_{1}$ \\
sex & Sex (male; female) & $x_{2}$ \\
marstatus & Marital status (divorced, married, \\
bachelor) & $x_{3}$ \\
location & Location of crime (hotel, residence, \\
closed area, open area) & Time of arrest \\
time & Day ( 7.00 am $-7.00 \mathrm{pm})$ & $x_{4}$ \\
& Night (7.01 pm $-12.00 \mathrm{am})$ & $x_{5}$ \\
fines & Early Morning $(12.01$ am $-6.59 \mathrm{am})$ & \\
\hline
\end{tabular}

Table 2. Value for sex, marital status, location and time

\begin{tabular}{ccccc}
\hline value & sex & marstatus & location & time \\
\hline 1 & Female & Single & Open Area & Day \\
2 & Male & Married & Closed Area & Night \\
3 & & Divorced & Residence & Early Morning \\
4 & & & Hotel & \\
\hline
\end{tabular}


Table 3. Raw dataset for khalwat offences

\begin{tabular}{cccccc}
\hline Case No & age & sex & mar status & location & time \\
& $\boldsymbol{x}_{\mathbf{1}}$ & $\boldsymbol{x}_{\mathbf{2}}$ & $\boldsymbol{x}_{\mathbf{3}}$ & $\boldsymbol{x}_{\mathbf{4}}$ & $\boldsymbol{x}_{\mathbf{5}}$ \\
\hline $11003-143-0012-2015$ & 17 & female & bachelor & residence & early morning \\
$11008-143-0001-2015$ & 28 & male & married & hotel & night \\
$11003-143-0024-2015$ & 59 & male & divorced & residence & early morning \\
$11005-143-0107-2015$ & 37 & female & divorced & residence & early morning \\
$\ldots$ & $\ldots$ & $\ldots$ & $\ldots$ & $\ldots$ & $\ldots$ \\
$11009-143-0028-2015$ & 28 & female & divorced & closed area & early morning \\
\hline
\end{tabular}

Table 4. Converted data set according to value defined in Table 3

\begin{tabular}{cccccc}
\hline \multirow{2}{*}{ Case No } & age & sex & mar status & location & time \\
& $\boldsymbol{x}_{\mathbf{1}}$ & $\boldsymbol{x}_{\mathbf{2}}$ & $\boldsymbol{x}_{\mathbf{3}}$ & $\boldsymbol{x}_{\mathbf{4}}$ & $\boldsymbol{x}_{\mathbf{5}}$ \\
\hline $11003-143-0012-2015$ & 17 & 1 & 1 & 3 & 3 \\
$11008-143-0001-2015$ & 28 & 2 & 2 & 4 & 2 \\
$11003-143-0024-2015$ & 59 & 2 & 3 & 3 & 3 \\
$11005-143-0107-2015$ & 37 & 1 & 3 & 3 & 3 \\
$\ldots$ & $\ldots$ & $\ldots$ & $\ldots$ & $\ldots$ & $\ldots$ \\
$11009-143-0028-2015$ & 28 & 1 & 3 & 2 & 3 \\
\hline
\end{tabular}

Based on the data collected and ANFIS parameters need, rules are generated using numerical data introduced by [12]. These rules will be used in the layers in ANFIS. Table 5 is a set of data that has been sorted by age.

\subsubsection{Generating rules using numerical data}

In generating the rules, eight steps have to be considered:

Step 1 : Identify the number of data collected, $A=75$

Step 2 : Identify the number of attributes, $B=6$ (age, sex, marstatus, location, time, fines)

Step 3 : Calculate the total number of rules, $R=\frac{A}{B}=\frac{75}{6}=12$

Step 4 : Data are sorted according to age as shown in Table 4.

Step 5 : The maximum value is identified for each variable

Step 6 : The fuzzy numbers in Table 4 forms the antecedents and consequent parts of the rule.

Step 7 : Rule 1 is framed as

If $\left(x_{1}\right.$ is 17$)$ or $\left(x_{2}\right.$ is female $)$ or $\left(x_{3}\right.$ is bachelor) or $\left(x_{4}\right.$ is hotel $)$ or $\left(x_{5}\right.$ is earlymorning) then $y$ is 2.7.

Step 8 : To frame the next rule, the next 6 data are taken and the $4^{\text {th }}$ and $5^{\text {th }}$ steps are repeated and generated rule 1 are shown in Table 5.

Table 5. First frame of data to generate rule 1

\begin{tabular}{ccccccc}
\hline Case No & age & sex & mar status & location & time & fines \\
& $\boldsymbol{x}_{\mathbf{1}}$ & $\boldsymbol{x}_{\mathbf{2}}$ & $\boldsymbol{x}_{\mathbf{3}}$ & $\boldsymbol{x}_{\mathbf{4}}$ & $\boldsymbol{x}_{\mathbf{5}}$ & $\boldsymbol{y}$ \\
\hline $11009-143-0016-2015$ & 15 & 1 & 1 & 3 & 3 & 2.0 \\
$11004-143-0120-2014$ & 15 & 1 & 1 & 3 & 3 & 2.6 \\
$11003-143-0012-2015$ & 17 & 1 & 1 & 3 & 3 & 2.3 \\
$11006-143-0072-2015$ & 17 & 1 & 1 & 4 & 2 & 2.5 \\
$11006-143-0073-2015$ & 17 & 1 & 1 & 4 & 2 & 2.5 \\
$11005-143-0141-2015$ & 17 & 1 & 1 & 4 & 2 & 2.7 \\
\multicolumn{7}{c}{ Maximum values for fuzzy variables } \\
Rule 1 & 17 & 1 & 1 & 4 & 3 & 2.7 \\
\hline
\end{tabular}

\subsubsection{Predicting output variable using linear equation}

Based on 12 rules framed earlier, output variable, $c$ for each rule equation is then predicted for linear equation as follow:

$$
y=p_{i}^{1} x_{1}+p_{i}^{2} x_{2}+p_{i}^{3} x_{3}+p_{i}^{4} x_{4}+p_{i}^{5} x_{5}+c_{i}
$$

while parameter $p_{i}^{j}$ is predicted using the linear equation using the formula introduced by [12] as follow:

$$
p_{i}^{j}=\frac{\frac{\operatorname{mean}(y)}{\max \left(x_{j}\right)}+\frac{\operatorname{mean}(y)}{\text { mean }\left(x_{j}\right)}}{\text { mean }(y)(\text { no.atrributes })}
$$

where $j=1,2,3,4,5$ and $i=1,2,3 \ldots 11,12$. 
The predicted fuzzy values and generated rules are used in ANFIS method to estimate fines amount are presented in Table 6. For example:

Rule 1: If ( $x_{1}$ is young) or ( $x_{2}$ is female) or ( $x_{3}$ is bachelor) or ( $x_{4}$ is hotel) or ( $x_{5}$ is earlymorning) then $y$ is high, $y_{1}=p_{1}^{1} x_{1}+p_{1}^{2} x_{2}+p_{1}^{3} x_{3}+p_{1}^{4} x_{4}+p_{1}^{5} x_{5}+c_{1}$.

$$
p_{i}^{j}=\frac{\frac{\operatorname{mean}(y)}{\max \left(x_{j}\right)}+\frac{\operatorname{mean}(y)}{\text { mean }\left(x_{j}\right)}}{\text { mean }(y)(\text { no.atrributes })}=\frac{\frac{2.4}{17}+\frac{2.4}{16}}{(2.4)(5)}=0.02
$$

Table 6. Predicted fuzzy values for $p_{i}^{j}$ for Rule 1

\begin{tabular}{|c|c|c|c|c|c|}
\hline & age & $\operatorname{sex}$ & mar status & location & time \\
\hline & $x_{1}$ & $x_{2}$ & $x_{3}$ & $x_{4}$ & $x_{5}$ \\
\hline $\operatorname{mean}(y)$ & \multicolumn{5}{|c|}{2.4} \\
\hline $\max \left(x_{j}\right)$ & 17 & 1 & 1 & 4 & 3 \\
\hline $\operatorname{mean}\left(x_{j}\right)$ & 16 & 1 & 1 & 4 & 3 \\
\hline no. of attributes & \multirow{3}{*}{$\begin{array}{c}p_{1}^{1} \\
0.02\end{array}$} & \multirow{3}{*}{$\begin{array}{c}p_{1}^{2} \\
0.40\end{array}$} & 5 & \multirow{3}{*}{$\begin{array}{c}p_{1}^{4} \\
0.11\end{array}$} & \multirow{3}{*}{$\begin{array}{c}p_{1}^{5} \\
0.15\end{array}$} \\
\hline mean $(y)+$ mean $(y)$ & & & $p_{1}^{3}$ & & \\
\hline$\frac{\max \left(x_{j}\right)}{\text { nean }(y) \text { mean }\left(x_{j}\right)}$ & & & 0.40 & & \\
\hline
\end{tabular}

$c_{i}$ For all rules are calculated using linear equation with the value for each rule framed. For example, $c_{1}$ is calculated as follows:

$$
\begin{aligned}
& c_{1}=y_{1}-p_{1}^{1} x_{1}+p_{1}^{2} x_{2}+p_{1}^{3} x_{3}+p_{1}^{4} x_{4}+p_{1}^{5} x_{5} \\
& c_{1}=2.7-((0.02)(17)+(0.40)(1)+(0.40)(1)+(0.11)(4)+(0.15)(3)) \\
& c_{1}=0.67
\end{aligned}
$$

The $c_{i}$ values for Rule 1 to Rule 12 are presented in Table 7.

Table 7. Predicted fuzzy value for $p_{i}^{j}, c_{i}$

\begin{tabular}{ccccccc}
\hline & $p_{i}^{1}$ & $p_{i}^{2}$ & $p_{i}^{3}$ & $p_{i}^{4}$ & $p_{i}^{5}$ & $c_{i}$ \\
\hline Rule 1 & 0.02 & 0.4 & 0.4 & 0.11 & 0.15 & 0.67 \\
Rule 2 & 0.02 & 0.23 & 0.4 & 0.13 & 0.15 & 0.51 \\
Rule 3 & 0.02 & 0.21 & 0.4 & 0.11 & 0.14 & 0.72 \\
Rule 4 & 0.02 & 0.27 & 0.22 & 0.13 & 0.17 & 0.33 \\
Rule 5 & 0.02 & 0.25 & 0.2 & 0.1 & 0.15 & 0.59 \\
Rule 6 & 0.02 & 0.2 & 0.4 & 0.11 & 0.14 & 0.82 \\
Rule 7 & 0.01 & 0.22 & 0.17 & 0.11 & 0.15 & 0.88 \\
Rule 8 & 0.01 & 0.22 & 0.15 & 0.11 & 0.17 & 0.85 \\
Rule 9 & 0.01 & 0.23 & 0.17 & 0.11 & 0.14 & 0.84 \\
Rule 10 & 0.01 & 0.25 & 0.14 & 0.13 & 0.15 & 0.89 \\
Rule 11 & 0.01 & 0.22 & 0.15 & 0.11 & 0.14 & 0.68 \\
Rule 12 & 0.01 & 0.22 & 0.14 & 0.11 & 0.13 & 0.72 \\
\hline
\end{tabular}

\subsection{AHP solution}

In the study, five criteria involved to estimate the fines amount. However, judges also have different thoughts regarding which domain factor contribute to the order. This situation proved in [11] where some cases that have the same values show different fines amount concerning a different judge. The difference will affect the training data and the final result at once. A survey had been conducted to find the weight of each criterion using AHP to ensure the consistency of the results. Two sections were surveyed which is first to identify the experience of judges in handling the khalwat cases and the second one is to calculate the domain factor of each criterion defined by the judges. 


\subsubsection{Finding weightage judge experience}

Based on the survey collected, here are the experience of each judge as present in Table 8.

\begin{tabular}{cc}
\multicolumn{2}{c}{ Table 8. Judge years of experience } \\
\hline Judge Name & Experience (years) \\
\hline Judge A & 15 \\
Judge B & 20 \\
Judge C & 4 \\
Judge D & 2 \\
\hline
\end{tabular}

Step 1: Sum all the years of experience, $Y$

$$
Y=20+15+4+2=41
$$

Step 2: Find the experience weightage by dividing each experience by $Y$

$$
\text { Experience Weightage, } E \cdot W_{\mathrm{n}}=\frac{Y_{n}}{Y}
$$

For example, Judge A Experience Weightage, $E . W_{\mathrm{A}}=\frac{Y_{A}}{Y}$

$$
\text { E. } W_{\mathrm{A}}=\frac{15}{41}=0.37
$$

The weightage of all judge experience are tabulated in Table 9.

Table 9. Judge experience weightage

\begin{tabular}{cc}
\hline Judge Name & Weightage \\
\hline Judge A & 0.37 \\
Judge B & 0.49 \\
Judge C & 0.10 \\
Judge D & 0.05 \\
\hline
\end{tabular}

\subsubsection{Finding weightage criteria}

Step 1: Compare the factors. 10 pair-wise comparisons were questioned to four judges in the study area.

a. Age compared with Sex

b. Age compared with Marital Status

c. Age compared with Time of Arrest

d. Age compared with Location of Arrest

e. Sex compared with Marital Status

f. Sex compared with Time of Arrest

g. Sex compared with Location of Arrest

h. Marital Status compared with Time of Arrest

i. Marital Status compared with Location of Arrest

j. Time of Arrest compared with Location of Arrest

Step 2: The degree of scale by the four judges was collected and the result is completed in the matrix for each judge. Table 10 shows an example of pair-wise comparison by judge A.

Table 10. Pair-wise comparison result by judge A

\begin{tabular}{cccccc}
\hline Factor & Age & Sex & $\begin{array}{c}\text { Marital } \\
\text { Status }\end{array}$ & $\begin{array}{c}\text { Time of } \\
\text { Arrest }\end{array}$ & $\begin{array}{c}\text { Location of } \\
\text { Arrest }\end{array}$ \\
\hline Age & 1.00 & 8.00 & 0.13 & 0.14 & 0.17 \\
Sex & 0.13 & 1.00 & 0.17 & 0.17 & 0.17 \\
Marital Status & 8.00 & 6.00 & 1.00 & 0.33 & 6.00 \\
Time of Arrest & 7.00 & 6.00 & 3.00 & 1.00 & 7.00 \\
Location of Arrest & 6.00 & 6.00 & 0.17 & 0.14 & 1.00 \\
Total & 22.13 & 27.00 & 4.46 & 1.79 & 14.33 \\
\hline
\end{tabular}

Step 3: Normalized the pair-wise comparison for each judge. As shown in Table 11, the normalized values are presented as priority vector of criteria by all the judges. 
Table 11 . Priority vector of criteria by all judges

\begin{tabular}{ccccc}
\hline & $\begin{array}{c}\text { Judge A } \\
\text { Priority Vector or } \\
\text { Weight }\end{array}$ & $\begin{array}{c}\text { Judge B } \\
\text { Priority Vector or } \\
\text { Weight }\end{array}$ & $\begin{array}{c}\text { Judge C } \\
\text { Priority Vector or } \\
\text { Weight }\end{array}$ & $\begin{array}{c}\text { Judge D } \\
\text { Priority Vector or } \\
\text { Weight }\end{array}$ \\
\hline Age & 0.09 & 0.26 & 0.08 & 0.07 \\
Sex & 0.04 & 0.03 & 0.03 & 0.03 \\
Marital Status & 0.28 & 0.31 & 0.56 & 0.54 \\
Time of Arrest & 0.45 & 0.17 & 0.20 & 0.21 \\
Location of Arrest & 0.14 & 0.23 & 0.13 & 0.15 \\
\hline
\end{tabular}

\subsubsection{Finding weightage criteria in consideration with judge experience}

Step 1: Multiply each factor weightage with judge experience weightage.

Step 2: Total the result for each factor to get the final weightage. The results are shown in Figure 1.

\begin{tabular}{|c|c|c|c|c|c|c|c|c|c|c|c|c|c|}
\hline \multirow{2}{*}{$\begin{array}{l}\text { Judge } \\
\text { Criteria }\end{array}$} & \multicolumn{3}{|c|}{ Judge A } & \multicolumn{3}{|c|}{ Judge B } & \multicolumn{3}{|c|}{ Judge C } & \multicolumn{3}{|c|}{ Judge D } & \multirow{2}{*}{$\begin{array}{c}\text { Final } \\
\text { Weightage, } w \\
\text { Total }\end{array}$} \\
\hline & $\begin{array}{l}\text { C. W } \\
\text { AXn }\end{array}$ & $\begin{array}{c}E . W \\
\text { A }\end{array}$ & $\begin{array}{c}\text { Multiplied, } \\
w_{A}\end{array}$ & $\begin{array}{c}C . W \\
\mathrm{BXn}\end{array}$ & $\begin{array}{c}E . W \\
\text { B }\end{array}$ & $\begin{array}{c}\text { Multiplied, } \\
w_{B}\end{array}$ & $\begin{array}{c}C . W \\
\mathrm{CXn}\end{array}$ & $\begin{array}{c}E . W \\
\mathrm{c}\end{array}$ & $\begin{array}{c}\text { Multiplied, } \\
w_{C}\end{array}$ & $\begin{array}{c}\text { C. W } \\
\text { DXn }\end{array}$ & $\begin{array}{c}E . W \\
\text { D }\end{array}$ & $\begin{array}{c}\text { Multiplie } \\
\mathrm{d}, w_{D}\end{array}$ & \\
\hline Age & 0.09 & 0.37 & 0.034 & 0.26 & 0.49 & 0.128 & 0.08 & 0.10 & 0.008 & 0.07 & 0.05 & 0.003 & 0.174 \\
\hline Sex & 0.04 & 0.37 & 0.014 & 0.03 & 0.49 & 0.012 & 0.03 & 0.10 & 0.003 & 0.03 & 0.05 & 0.001 & 0.030 \\
\hline $\begin{array}{c}\text { Marital } \\
\text { Status }\end{array}$ & 0.28 & 0.37 & 0.105 & 0.31 & 0.49 & 0.153 & 0.56 & 0.10 & 0.056 & 0.54 & 0.05 & 0.027 & 0.340 \\
\hline $\begin{array}{l}\text { Time of } \\
\text { Arrest }\end{array}$ & 0.45 & 0.37 & 0.167 & 0.17 & 0.49 & 0.083 & 0.20 & 0.10 & 0.020 & 0.21 & 0.05 & 0.011 & 0.281 \\
\hline $\begin{array}{l}\text { Location } \\
\text { of Arrest }\end{array}$ & 0.14 & 0.37 & 0.050 & 0.23 & 0.49 & 0.114 & 0.13 & 0.10 & 0.013 & 0.15 & 0.05 & 0.008 & 0.185 \\
\hline
\end{tabular}

Figure 1. Result of final criteria weightage

\subsection{ANFIS enhanced with AHP solution}

Based on (4), output variable, $\boldsymbol{c}$ for each rule equation is then predicted again for linear equation enhanced with AHP weightage result as in (5) and (6). The results are then shown in Table 12.

$$
\begin{aligned}
& y=p_{i}^{1} w_{1} x_{1}+p_{i}^{2} w_{2} x_{2}+p_{i}^{3} w_{3} x_{3}+p_{i}^{4} w_{4} x_{4}+p_{i}^{5} w_{5} x_{5}+c_{i} \\
& c_{1}=y_{1}-p_{i}^{1} w_{1} x_{1}+p_{i}^{2} w_{2} x_{2}+p_{i}^{3} w_{3} x_{3}+p_{i}^{4} w_{4} x_{4}+p_{i}^{5} w_{5} x_{5} \\
& c_{1}=2.7-((0.02)(0.194)(17)+(0.40)(0.029)(1)+(0.40)(0.338)(1)+ \\
& \quad(0.11)(0.196)(4)+(0.15)(0.252)(3)) \\
& c_{1 \text { new }}=2.29
\end{aligned}
$$

Table 12. Predicted fuzzy value for $p_{i}^{j}, c_{i(\text { new })}$

\begin{tabular}{cccccccc}
\hline & $p_{i}^{1}$ & $p_{i}^{2}$ & $p_{i}^{3}$ & $p_{i}^{4}$ & $p_{i}^{5}$ & $c_{i}$ & $c_{i(\text { new })}$ \\
\hline Rule 1 & 0.02 & 0.4 & 0.4 & 0.11 & 0.15 & 0.67 & 2.29 \\
Rule 2 & 0.02 & 0.23 & 0.4 & 0.13 & 0.15 & 0.51 & 2.27 \\
Rule 3 & 0.02 & 0.21 & 0.4 & 0.11 & 0.14 & 0.72 & 2.38 \\
Rule 4 & 0.02 & 0.27 & 0.22 & 0.13 & 0.17 & 0.33 & 2.45 \\
Rule 5 & 0.02 & 0.25 & 0.2 & 0.1 & 0.15 & 0.59 & 2.50 \\
Rule 6 & 0.02 & 0.2 & 0.4 & 0.11 & 0.14 & 0.82 & 2.56 \\
Rule 7 & 0.01 & 0.22 & 0.17 & 0.11 & 0.15 & 0.88 & 2.56 \\
Rule 8 & 0.01 & 0.22 & 0.15 & 0.11 & 0.17 & 0.85 & 2.56 \\
Rule 9 & 0.01 & 0.23 & 0.17 & 0.11 & 0.14 & 0.84 & 2.56 \\
Rule 10 & 0.01 & 0.25 & 0.14 & 0.13 & 0.15 & 0.89 & 2.59 \\
Rule 11 & 0.01 & 0.22 & 0.15 & 0.11 & 0.14 & 0.68 & 2.37 \\
Rule 12 & 0.01 & 0.22 & 0.14 & 0.11 & 0.13 & 0.72 & 2.55 \\
\hline
\end{tabular}

\section{RESULTS AND DISCUSSIONS}

In this paper, 75 cases were trained, and 30 cases were tested with ANFIS and ANFIS+AHP. The cases in Table 13 are compared because of the same value for sex, marital status, time of arrest and location of arrest criteria. However, the value of age is different. The result shows that the human judgement is inconsistent where the fines amount for a 25 -year-old man is lower than a 23-year-old man with the same 
value for the other criteria. The age difference is only two years, and it is quite confusing. By using ANFIS, the gap of fines amount is smaller where ANFIS+AHP shows a very consistent result for the range of age under 35 years old.

Table 13. Result comparison between human judgement, ANFIS and ANFIS+AHP

\begin{tabular}{ccccc}
\hline Case No & Age & $\begin{array}{c}\text { Human } \\
\text { Judgement }\end{array}$ & ANFIS & ANFIS+AHP \\
\hline $11003-143-0005-2016$ & 23 & 2.9 & 2.7 & 2.8 \\
$11004-143-0080-2016$ & 24 & 2.9 & 2.8 & 2.8 \\
$11005-143-0029-2016$ & 25 & 2.7 & 2.7 & 2.8 \\
$11003-143-0034-2015$ & 31 & 2.9 & 2.8 & 2.8 \\
$11005-143-0047-2016$ & 32 & 2.7 & 2.8 & 2.8 \\
\hline
\end{tabular}

ANFIS+AHP has processed the equation and present the result in its range. As an example, for the same value of other criteria ( $\mathrm{sex}=$ female, marital status=single, location of arrest=open area, time of arrest $=$ day) and only age is different, here Table 14 is the range for fines amount.

Table 14. Fines amount range based on range of age

\begin{tabular}{cc}
\hline Range of Age & $\begin{array}{c}\text { Fines Amount using } \\
\text { ANFIS+AHP }\end{array}$ \\
\hline $0-16$ & 2.6 \\
$17-51$ & 2.7 \\
$52-85$ & 2.8 \\
86 and above & 2.9 \\
\hline
\end{tabular}

\section{CONCLUSION}

This paper proposed ANFIS+AHP to estimate fines amount based on previous judgments. 75 datasets were used for training, and 30 datasets were used for testing. The estimation considered five inputs and one single output based on case fact from the Syariah criminal files in the studied department. The result of the proposed method has proven that ANFIS+AHP is an efficient way to estimate the fines and helps the judge make a preliminary judgment at once.

\section{ACKNOWLEDGEMENTS}

The authors would like to thank the Department of Syariah Judiciary State of Terengganu especially Y.A Tn Hj Kamalruazmi bin Ismail, the Syariah Highcourt Judge for their active cooperation and the data provided.

\section{REFERENCES}

[1] S. D. James, et al., "Multiple Criteria Decision Making, Multiattribute Utility Theory: The Next Ten Years," Management Science, vol. 38, pp. 645-654, 1992.

[2] W. Jyrki, et al., "Multiple Criteria Decision Making, Multiattribute Utility Theory: Recent Accomplishments and What Lies Ahead," Journal Management Science, vol. 54, pp. 1336-1349, 2008.

[3] T. Faisal, et al., "Adaptive Neuro-Fuzzy Inference System for diagnosis risk in dengue patients," Expert Systems with Applications, vol. 39, pp. 4483-4495, 2012.

[4] R. Appiah, "Implementation of adaptive neuro fuzzy inference system for malaria diagnosis," A case study at Kwesimintsim Polyclinic, PhD diss., 2016.

[5] R. Nohria and P. S. Mann, "Diagnosis of Hypertension Using Adaptive Neuro-Fuzzy Inference System," International Journal of Computer Science and Technology, vol. 6, pp. 36-40, 2015.

[6] M. A. Abushariah, et al., "Automatic heart disease diagnosis system based on artificial neural network (ANN) and adaptive neuro-fuzzy inference systems (ANFIS) approaches," Journal of software engineering and applications, vol. 7, pp. 1055, 2014.

[7] N. Ziasabounchi and I. Askerzade, "ANFIS based classification model for heart disease prediction," International Journal of Electrical \& Computer Sciences IJECS-IJENS, vol. 14, pp. 7-12, 2014.

[8] D. Bohra and S. Bhatia, "Portfolio return modelling using ANFIS," International Journal of Engineering, vol. 1, pp. 1-4, 2012.

[9] M. A. Boyacioglu and D. Avci, "An adaptive network-based fuzzy inference system (ANFIS) for the prediction of stock market return: the case of the Istanbul stock exchange," Expert Systems with Applications, vol. 37, pp.7908-7912, 2010. 
[10] L. Abdullah and F. N. Azman, "Weights of obesity factors using analytic hierarchy process," Int. J. Res. Rev. App. Sci, vol. 7, pp. 57-83, 2011.

[11] A. F. Mazlam, et al., "Estimation of Fines Amount in Syariah Criminal Offences Using Adaptive Neuro-Fuzzy Inference System (ANFIS)," Journal of Telecommunication, Electronic and Computer Engineering (JTEC), vol. 9, pp. 153-156, 2017.

[12] A. S. Kumar, "Generating rules for advanced fuzzy resolution mechanism to diagnosis heart disease," International Journal of Computer Applications, vol. 77, 2013.

\section{BIOGRAPHIES OF AUTHORS}
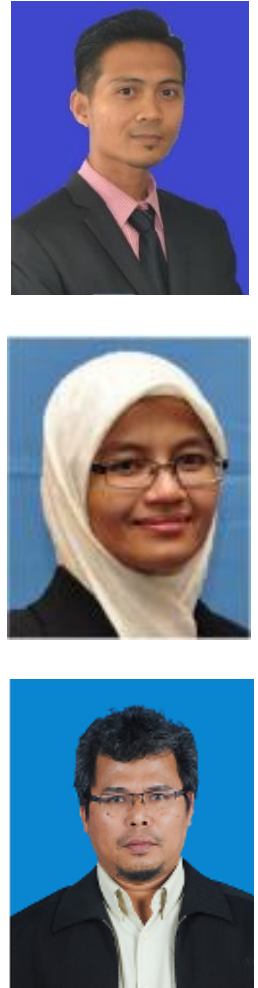

Ahmad Fitri Mazlam is an ICT Officer in Institut Pendidikan Guru Kampus Dato' Razali Ismail and a Post-Graduate Student at School of Informatics and Applied Mathematics, Universiti Malaysia Terengganu. He obtained Bachelor Degree in Science (Computer) from Universiti Teknologi Malaysia in 2005. His researches are in fields of Decision Support System, Artificial Intelligence and Artificial Neural Network. Recently, system's application on syariah judiciary department has been tackled and his article has been published in JTEC in 2017. Besides, he is also involved in NGOs, student associations, and managing non-profit foundation.

Wan Nural Jawahir Hj Wan Yussof received her B.IT in Software Engineering and M.Sc. in Artificial Intelligence from Kolej Universiti Sains dan Teknologi Malaysia. In 2014, she obtained her Ph.D. from Universiti Malaysia Terengganu. She is currently a senior lecturer at School of Informatics and Applied Mathematics, Universiti Malaysia Terengganu. Her research interests are in 2D/3D image analysis and underwater video processing.

Rabiei Mamat received his M.Sc. degree in High Performance System from University College of Science and Technology Malaysia (KUSTEM) in 2004 and getting his Ph.D. in Information Technology from the Universiti Tun Hussein Onn (UTHM) in 2014. Currently he is a lecturer in School of Informatics and Applied Mathematics, Universiti Malaysia Terengganu (UMT). His teaching topics includes Web and Mobile Application Development and Programming. His research interests include Soft Computing and Data Mining. 